\title{
Preface for Thematic Section: Slag Granulation
}

\author{
Sharif Jahanshahi ${ }^{1,2}$
}

Published online: 31 May 2019

(c) The Minerals, Metals \& Materials Society 2019

\section{Introduction}

Granulation of molten metallurgical slags is a value-adding process that converts a low-value byproduct (and sometimes waste) into a saleable product with multiple uses by the building and construction industries. In particular, when ironmaking slag is granulated and is substituted for Portland Cement, the environmental and economic benefits become very significant and attractive to the industry.

Traditionally, metallurgical slags have been air cooled in slag pots or slag pits. Slag pot cooling is a slow process, thus allowing crystallization of various mineral phases as well as the separation of metallic and matte phases into droplets. The slag that is poured into pits is cooled by air and sprayed water. The slow-cooled slag is crushed, sieved, and ground before recovery of valuable metals via floatation, magnetic separation, or leaching. Thus, investment in equipment and heavy machinery is required as well as the operating cost of such equipment/processes. A key reason for the granulation of melts is to avoid the cost and energy required to crush and grind the material. For these reasons, granulation of slags, mattes, and some alloys are very popular in the nonferrous industry.

Fast cooling of molten silicate slags suppresses the crystallization of mineral phases and results in the formation of a glassy/amorphous phase. The formation of the glassy phase is advantageous when the slag will be used as a substitute for clinker in the Portland cement or when high resistance to leaching of metal oxides in the slag is required.

When molten iron blast furnace slag is rapidly quenched, it forms a solid product which is $>95 \%$ amorphous in structure. This material has a high cementitious property and can replace up to $70 \%$ of clinker in Ordinary Portland Cement (OPC). Given the huge market (over 2 billion tons per year)

\footnotetext{
Sharif Jahanshahi

Sharif@Metalogical.solutions

Meta-Logical Solutions, Pty Ltd., Melbourne, Australia

2 UNSW, Sydney, Australia
}

for OPC, the demand for the fast-cooled or ground granulated BF slag has been increasing and growing rapidly in developing countries.

The fayalite-type slags produced by the copper/nickel smelting and converting processes are not cementitious, and their uses include abrasive material for sandblasting and ball milling. In order to use such slags for construction of roads or similar applications, their resistance to leaching must be increased considerably. It is well established that heavy metals such as arsenic can be locked in the silicate structure of rapidly cooled fayalite slags. In contrast, the slow-cooled slags have considerably lower resistance to leaching of such metals.

\section{Alternative Approaches}

Slags have low thermal conductivity, and thus, to achieve high cooling rates, the stream of molten slag needs to be broken up into small droplets to increase the surface areato-volume ratio and enhance heat transfer. There are several different methods to granulate or atomize including using mechanical devices such as spinning disk or jets of water or air. However, the most commonly used process for melt granulation uses water jets.

Water granulation of slag has some shortcomings when measured against increasingly stringent requirements for sustainable operations. As a "wet" process, water granulation cannot recover high-grade waste heat from molten slags. The process consumes a large amount of water (about 1 ton of water per ton of slag is lost through evaporation) and may emit acid mist, $\mathrm{H}_{2} \mathrm{~S}$, and $\mathrm{SO}_{2}$, causing serious air pollution. Furthermore, the wet granulated slag has to be dewatered at a significant cost and then dried. The dewatering to $10-15 \%$ moisture and then drying consume significant energy as well as requiring much space and capital investment. As such, it is highly desirable that an alternative slag process could be developed to replace water granulation to meet the current and future needs of the steel industry. 
The concept of dry granulation and heat recovery was proposed in the 1970s. Several methods have been proposed, and some tested and trialed at pilot and demonstration plant scales.

As mentioned earlier, in order to achieve high cooling rates of melts with low thermal conductivity, the melt needs to be broken up into small droplets to increase the surface area for heat transfer. Three major approaches have been proposed and tested for this purpose. These include (1) air blasting (2) rotating drums and (3) spinning disk/cup. A fourth approach has been developed recently, which comprises injection of small steel spheres to absorb heat from the molten slag. In recent years, much progress has been made in research, development, and scale-up of these concepts to large pilot plants. Similarly, significant progress has been made in the development of a fundamental understanding of the process of physics that underpins successful scale-up of pilot plants to the demonstration of the technology.

In this thematic section of the Journal Sustainable Metallurgy, a small number of articles are presented, which cover the process fundamentals as well as process engineering and applications in the processing of industrial slags.

The work reported by So et al. [1] was aimed at the application of air blasting to granulation of stainless-steel slag and suppress dust formation through dicalcium silicate phase transformation. The results of this pilot-scale work, granulating at about $30 \mathrm{~kg} / \mathrm{min}$, confirmed that formation of the "dusting phase" ( $\gamma$-dicalcium silicate) in the solidified slag, and hence, a very stable product was successfully produced. This study covered the effects of slags composition, viscosity, and temperature as well as the velocity of air on particle size distribution and mineralogy of the granulated slag.

The second work by Vadillo et al. [2] is on physical modeling of air blast cross-flow atomization of cold fluids. This study was aimed at developing an improved understanding of how particle characteristic could be controlled when metallurgical slags are atomized in the cross-flow air granulation process. Vadillo et al. covered the effects of process parameters such as liquid viscosity and air-to-liquid ratio on the particle size distribution. Some interesting observations of the aspect ratio and formation of secondary atomization are reported in the cited paper.

The next work by Cooksey et al. [3] provides an overview of the design and operation of a dry slag granulation pilot plant at CSIRO. This overview covers some of the R\&D activities and findings on the design of rotating disk for atomization of melts, cyclonic fluidized granules, heat transfer, and recovery. The designed $100 \mathrm{~kg} / \mathrm{min}$ pilot plant has been used to validate the CFD (computation fluid dynamics) models that were developed for the scale of the process to 1-2 tons/min of molten slags. The results obtained demonstrate efficient granulation of ironmaking slags with very high glassy phase content that is very suitable for the production of cement.

The fourth and last paper of this thematic section is by Pan et al. [4] and covers CFD modeling of melt spreading behavior on spinning disks and cups. In this work, a CFD model has been used to study the effects of slag flow rate, spinning rate, depth of the cup, and angle of the side wall on the thickness of slag film and hence droplet size. Their results appear to be in accordance with observations made at CSIRO using high-speed images of the pilot plant.

The above-listed articles provide some insights into the process fundamentals and challenges that are being investigated as part of the technology development by various R\&D groups in Europe, Canada, Australia, and China.

\section{References}

1. Lindvall M, So LLC, Mahdi M, Bolen J, Nell J, Metcalfe D, Mostaghel S, Sundqvist O (2019) Stabilization of stainless steel slag via air granulation. J Sustain Metall. https://doi.org/10.1007/ s40831-019-00212-2

2. Vadillo A, Mostaghel S, Barati M (2019) Air-blast crossflow atomization of cold fluids. J Sustain Metall. https://doi. org/10.1007/s40831-018-00207-5

3. Cooksey M, Guiraud A, Kuan B, Pan Y (2019) Design and operation of dry slag granulation pilot plant. J Sustain Metall. https:// doi.org/10.1007/s40831-019-00214-0

4. Pan Y, Zhao M, Ma P, Li J, Huo Z, Li H (2019) CFD modeling of melt spreading behavior on spinning discs and cups for centrifugal granulation of molten slag. J Sustain Metall. https://doi. org/10.1007/s40831-019-00213-1

Publisher's Note Springer Nature remains neutral with regard to jurisdictional claims in published maps and institutional affiliations. 